Article

\title{
Genome-Wide Identification and Expression Analysis of the Strawberry FvbZIP Gene Family and the Role of Key Gene FabZIP46 in Fruit Resistance to Gray Mold
}

\author{
Bei Lu ${ }^{1}$, Yuanhua Wang ${ }^{2,3}$, Geng Zhang ${ }^{2,3}$, Yingna Feng ${ }^{2,3}$, Zhiming Yan ${ }^{2,3}$, Jianhua $\mathrm{Wu}^{2,3, *}$ \\ and Xuehao Chen ${ }^{1, *}$ \\ 1 School of Horticulture and Plant Protection, Yangzhou University, Yangzhou 225000, China; \\ yzulubei@163.com \\ 2 Department of Agronomy and Horticulture, Jiangsu Vocational College of Agriculture and Forestry, \\ Jurong 212400, China; wangyuanhua0511@163.com (Y.W.); gengzhang@jsafc.edu.cn (G.Z.); \\ fengyingna88@126.com (Y.F.); yanzhim@jsafc.edu.cn (Z.Y.) \\ 3 Engineering and Technical Center for Modern Horticulture, Nanjing 210000, China \\ * Correspondence: wujianhua@jsafc.edu.cn (J.W.); xhchen@yzu.edu.cn (X.C.); Tel.: +86-159-0529-0666 (J.W.); \\ +86-0514-87971894 (X.C.)
}

Received: 13 August 2020; Accepted: 11 September 2020; Published: 14 September 2020

\begin{abstract}
A total of 54 FvbZIP genes were identified from the strawberry genome. These genes were found to be unevenly distributed on seven different chromosomes, and two of the genes had no matching chromosomal localization. FvbZIP genes were divided into 10 subfamilies according to protein sequence, and the structures of these genes were found to be highly conserved. Based on the bioinformatics analysis of FvbZIP genes, the expression of FabZIP genes changed during different stages of its growth and of its infection with gray mold disease. FabZIP46 was substantially upregulated, and its expression remained relatively high. FabZIP46 was cloned from cultivated strawberries by homologous cloning. The results of a transient transgenic assay revealed that the damage to the fruit tissue was markedly alleviated in strawberries overexpressing FabZIP46, with the incidence rate being substantially lower than that in the control group. By contrast, a brief silencing of FabZIP46 had the opposite effect. The results revealed that FabZIP46 played a positive role in the resistance of strawberries to Botrytis cinerea. The study findings provide valuable insights into the role of bZIP transcription factors as well as a theoretical reference for the regulation of resistance to gray mold disease in strawberry fruit.
\end{abstract}

Keywords: strawberry; bZIP transcription factors; bioinformatics; FabZIP46; gray mold disease

\section{Introduction}

The strawberry (Fragaria $\times$ ananassa) is the most cultivated among the small berries in the world and has both ornamental and nutritional value. Strawberries are currently one of the main crops under protected cultivation, and China is one of the largest strawberry producers in the world. Owing to its small size, short fruit growth cycle, and high genetic transformation efficiency, the strawberry is a suitable model plant for fruit research [1,2]. Therefore, it plays a pivotal role in both commercial production and scientific research in the vegetable and fruit industry. However, the common cultivated strawberry is octoploid, so its genetic background is very complex, but via the diploid woodland strawberry (Fragaria vesca) we have completed the work of genome sequencing. The published strawberry genome sequence is valuable for identifying ideal agronomic traits and stress resistance genes in the strawberry at the genome level. The strawberry production industry in Jiangsu Province focuses on forcing cultivation, wherein the growth period lasts from September to April and the 
fruiting period lasts from December to April. The low temperature and low photoperiod during the fruiting stage have huge impacts on the growth and development of strawberries in that the plants are more susceptible to gray mold disease, which can severely affect the yield and quality of strawberries. Gray mold disease is a critical concern in agricultural production worldwide and caused by Botrytis cinerea Pers. B. cinerea is considered a critical pathogenic and necrotrophic fungus. A genomic analysis revealed that $B$. cinerea secretes approximately 40 types of toxins and can infect more than 200 different plant species both before and after harvesting, resulting in severe economic losses to agricultural production [3-5]. Gray mold disease is one of the most serious diseases in strawberries and affects as much as $60 \%$ of the fruit once infected. The infection may occur both before and after fruit harvesting, thus causing the fruit to rot and become inedible. In severe cases, infection can lead to a total loss of yield. Thus, gray mold disease greatly impedes the development of strawberry production [6].

Studies have indicated that transcription factors (TFs) are key regulators of gene expression and play a pivotal role in the complex molecular defense network of plant immunity $[7,8]$. Basic leucine zippers (bZIP) are a group of transcription factors commonly found in animals, plants, and microorganisms. They have a basic amino acid region composed of 60-80 amino acid residues and a highly conserved bZIP domain composed of leucine zippers [9]. Numerous studies have indicated that members of the bZIP gene family are involved in biological processes such as growth and development, senescence, hormone regulation, energy metabolism, pathogen defense, and abiotic stress in plants [10-14]. For example, ZmbZIP4 overexpression in maize can markedly promote the growth and development of roots. Chromatin immunoprecipitation revealed that $Z m b Z I P 4$ directly binds to the promoters of genes that are involved in root developments, such as ZmLRP1 and ZMSCR, thereby promoting their transcription [15]. Transcription factor CabZIP1 is expressed only in the roots and flowers of hot peppers, but not in the leaves, stems, and fruits. Arabidopsis transfected with CabZIP1 exhibits a dwarf phenotype. Therefore, this gene is inferred to be involved in plant growth and development [16]. Overexpression of CabZIP1 in Arabidopsis can enhance the resistance of the plants to Pseudomonas syringae pv. tomato (DC3000) and can induce the expression of resistance-related genes AtRP4 and AtRD29A in Arabidopsis [13]. OsbZIP71 in rice can directly bind to the promoters of abiotic stress-related genes OsNHX1 and COR413-TM1 to activate their transcription, thereby enhancing the resistance of the plant to drought and salt. This finding supports the importance of OsbZIP71 in abiotic stress responses [17]. Zhang et al. isolated LrbZIP1 from lily plants and found that overexpression of LrbZIP1 in tobacco markedly inhibited the growth of Fusarium oxysporum [18]. All of the above studies suggest that bZIP genes can function alone, collaboratively, or in a complex to regulate plant growth and development or to induce a defense response against pathogens.

Although the role of many members of the $b Z I P$ gene family has been widely investigated in various crops, little is known about their defense-related functions and regulatory mechanisms in strawberries. Among the identified FvbZIP transcription factors, Wang et al. defined those associated with drought and heat stress responses in strawberries [19]. No specific genes have been identified as playing a role in the disease resistance mechanisms of the strawberry. Therefore, to further investigate the role of the $b Z I P$ gene family in the disease resistance of strawberries, we conducted a bioinformatic analysis to analyze the strawberry genome from more perspectives; to systematically and comprehensively analyze the basic physical and chemical properties of strawberry FvbZIP genes; and to understand the subclassification, evolutionary relationships, chromosomal localization, and conservation of domains of the encoded proteins. Based on the bioinformatics analysis of FvbZIP genes in the woodland strawberry, we also explored the changes in the expression of octoploid strawberry FabZIP genes at seven stages after infection with B. cinerea. Based on the study of $b Z I P$ genes in the woodland strawberry, we expected to screen potential candidate genes related to disease resistance and verify the role of related genes in gray mold disease in cultivated strawberries. The study findings may provide theoretical support for disease prevention and development of disease resistance for strawberry breeding in the future. 


\section{Results and Analysis}

\subsection{Members of the bZIP Transcription Factor Family in Strawberries}

By using the conserved domain of bZIP as a probe, aligning the annotated genome, and manually deleting repetitive and redundant sequences, 54 transcription factors of the bZIP gene family were identified in the woodland strawberry. Four more genes were added compared to previous studies by Wang et al. [19]. According to the chromosomes on which these genes are located, all the FvbZIP transcription factors were systematically numbered from FvbZIP1 to FvbZIP54 (Table S1). Related information, including genetic mapping, initiation site, termination site, and protein sequence length, was also categorized. The number of amino acids in FvbZIP proteins ranges from 114 to 847, with an average of 370. FvbZIP31 is the smallest bZIP protein and has 114 amino acids (Table S1). By using the online tool ProtParam, the molecular mass of the 54 FvbZIP proteins was predicted to range from 13.51 to $93 \mathrm{kDa}$, and the isoelectric point ranged from 4.48 to 10.61 (Table S1). Moreover, protein subcellular localization prediction revealed that FvbZIP genes were principally located within the nucleus.

\subsection{Phylogenetic Relationships among the Family Members of bZIP Transcription Factors in Strawberries}

A comparison of multiple genome sequences allows researchers to investigate species that are understudied by providing information from the research of species that have been extensively studied [20]. To study the evolutionary relationship between FvbZIP genes in the strawberry and those in Arabidopsis and rice, a phylogenetic tree was constructed based on the amino acid sequences of strawberry, Arabidopsis, and rice bZIP proteins was constructed by using the software MEGA7.0 (Figure 1), and a separate phylogenetic tree of strawberry FvbZIP genes was constructed for reference (Figure 4). By referring to the clustering method of Jakoby et al., which classified the $b Z I P$ gene family according to the domain characteristics, the $b Z I P$ genes of strawberry, Arabidopsis, and rice were classified into 10 subfamilies, namely A, B, C, D, E, F, G, H, I, and S, by using a phylogenetic tree [21]. The analysis showed that $85 \%$ of the 54 FvbZIP proteins cluster predominantly with Arabidopsis bZIP proteins, which indicates their closer evolutionary relationship than with rice bZIP proteins. Both strawberries and Arabidopsis are dicotyledons and are thus more closely related and may share an evolutionary ancestor. According to the kinship division in the phylogenetic tree, the function of strawberry FvbZIP genes can be preliminarily predicted by referring to their homologous genes in Arabidopsis. FvbZIP genes were also divided into 10 subfamilies in the phylogenetic tree of the $b Z I P$ gene family of the strawberry, and the genes of the same subfamilies were clustered more closely together. Among these subfamilies, the proportion of members in subfamilies A, D, and S had a similar number of members; subfamily A was the largest with 12 members, and subfamily B was the smallest with only one member. In similar studies, the bZIP gene families of the grape and apple have also been classified into 10 categories [22,23]. No species-specific populations were found in the phylogenetic tree of strawberry FvbZIP genes. Despite the differences within each subfamily of different species, members within the same subfamily are fundamentally similar, which suggests that the evolution of $b Z I P$ genes in plants is relatively conserved. 


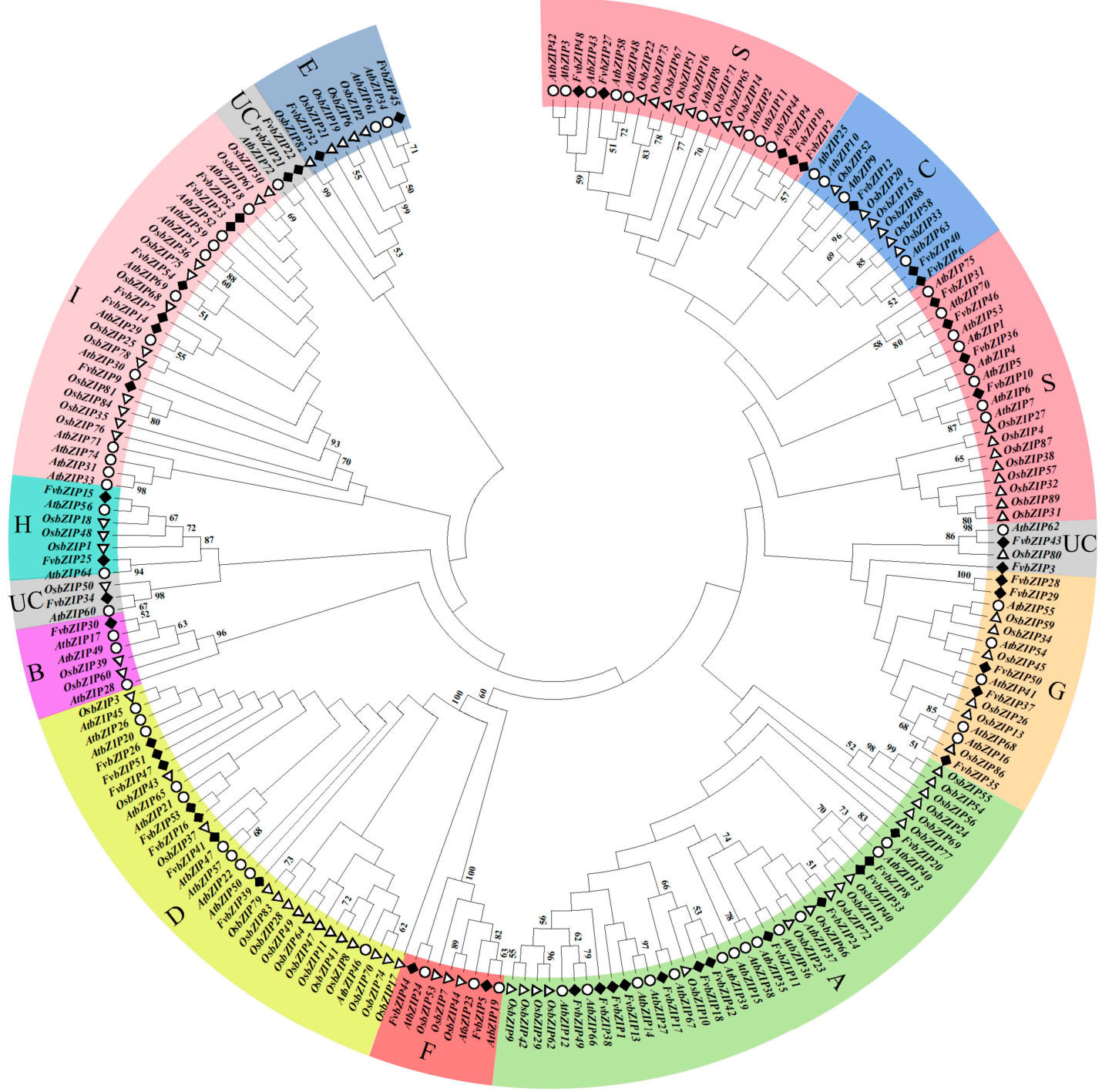

Figure 1. Phylogenetic analysis of bZIP genes. At represented A. thaliana, Os represented O. sativa. The phylogenetic tree was generated using the amino acid sequences of selected bZIP genes via NJ methods. All strawberry bZIP genes, together with their A. thaliana and O. sativa homologues, were classified into 10 groups.

\subsection{Chromosomal Localization and Analysis of the Gene Structure of Strawberry bZIP Genes}

According to the annotation information provided by NCBI, the chromosomal localization of the 54 genes was visualized through MapGene2Chromosome2. The results revealed that 52 genes were unevenly distributed on seven chromosomes and two genes, FvbZIP53 and FvbZIP54, had no matching chromosomal localization (Figure 2). Chromosome 2 contained the largest number of genes, 17. During a BLAST search of the structural domain of FvbZIP genes in the NCBI database, nine FvbZIP proteins were found to not only contain the typical bZIP conserved domains, but also other domains. Among these, FvbZIP35, FvbZIP37, and FvbZIP50 had the MFMR domain at the N-terminus of the bZIP domain. The MFMR domain has been reported to play a critical role in regulating protein-protein interactions [24]. FvbZIP16, FvbZIP26, FvbZIP39, FvbZIP41, FvbZIP47, FvbZIP51, and FvbZIP53 had a DELAY OF GERMINATION 1 (DOG1; PF14144) domain in addition to the bZIP conserved domain. DOG1 of Arabidopsis has been reported to be involved in the regulation of seed dormancy [25]. 


\begin{tabular}{|c|c|c|c|c|c|c|c|c|c|c|c|c|c|}
\hline \multicolumn{2}{|c|}{ ChromLG1 } & \multicolumn{2}{|c|}{ ChromLG2 } & \multicolumn{2}{|c|}{ ChromLG3 } & \multicolumn{2}{|c|}{ ChromLG4 } & \multicolumn{2}{|c|}{ ChromLG5 } & \multicolumn{2}{|c|}{ ChromLG6 } & \multicolumn{2}{|c|}{ ChromLG7 } \\
\hline $\begin{array}{l}0 \mathrm{Mb} \\
4 \mathrm{Mb}\end{array}$ & & FvbZIP3 & FvbZIP4 & & & & & FvbZIP28 & FvbZIP29 & FvbZIP40 & FvbZIP41 & FvbZIP49 & Fyb7|P50 \\
\hline $8 \mathrm{Mb}$ & & & FvbZIP6 & & & & & & -FvbZIP31 & & & & FvbZIP50 \\
\hline $\begin{array}{l}\text { FvbZIP1 } \\
12 \mathrm{Mb}\end{array}$ & FvbZIP2 & FvbZIP7- & & FvbZIP20 & & & & & & & & FvbZIP51 & \\
\hline $16 \mathrm{Mb}$ & & FvbZIP9 & FvbZIP8 & FvbZIP21- & FvbZIP22 & FvbZIP25 & -Fva7IP26 & FvbZIP32- & h7/P33 & FvbZIP44 & $\begin{array}{l}\text { Fvo } \\
\text { FvZIIP45 }\end{array}$ & & \\
\hline $20 \mathrm{Mb}$ & & FvbZIP11 & FvbZIP10 & FybZIP24 & FvbZIP23 & $F v b \angle I P 27$ & 1 viscio & Fvb $\angle I P 34$ & FvbZIP35 & FvbZIP46- & & & FvbZIP52 \\
\hline $24 \mathrm{Mb}$ & & $\begin{array}{l}\text { FvbZIP } 13 \\
\text { FvbZIP15 }\end{array}$ & $\begin{array}{l}\text { FvbZIP12 } \\
\text { FvbZIP14 }\end{array}$ & rVDLIR $\angle 4$ & & & & FvbZIP36 & & & FvbZIP47 & & \\
\hline $28 \mathrm{Mb}$ & & FvbŽIP17- & $\begin{array}{l}\text { Fvb } \\
\text { FvBIIP16 } 18\end{array}$ & & & & & FvbZIP38 & $\begin{array}{l}\text { FvbZIP37 } \\
\text { FvbZIP39 }\end{array}$ & & & & \\
\hline $32 \mathrm{Mb}$ & & & & & & & & & & FvbZIP48 & & & \\
\hline $36 \mathrm{Mb}$ & & & & & & & & & & & & & \\
\hline $10 \mathrm{Mb}$ & & & & & & & & & & & & & \\
\hline
\end{tabular}

Figure 2. Chromosome distribution of FvbZIP genes. The chromosome numbers are demonstrated at the top of each chromosome and the scale is in megabases (Mb). 
Multiple sequence alignment visualization was performed on the amino acid site in the amino acid conserved domain of the bZIP proteins of the strawberry. The results revealed that the $\mathrm{N}$-terminus of the bZIP conserved domain of FvbZIP proteins exhibited a N-X7-R/K motif, which formed the basic region of bZIP. In addition, one leucine was present for every seven other amino acids in the C-terminal direction after the nine amino acids of $\mathrm{R} / \mathrm{K}$, which formed the leucine zipper domain (Figure 3 ). The basic domain of FvbZIP32 was composed of Lys instead of Asn, which was consistent with that in the previously reported rice proteins OsbZIP21 and OsbZIP82 [26]. From Figure S1, it is evident that the bZIP conserved domains of Arabidopsis and strawberry proteins are almost identical, suggesting that, genetically, the strawberry is more closely related to Arabidopsis than to rice. These results indicate that the role of strawberry FvbZIP genes might be similar to that of Arabidopsis bZIP genes.

To further investigate the relationship among the protein components of the $b Z I P$ family, the online prediction tool MEME was used to predict 20 conserved motifs of the strawberry $b Z I P$ family (Figure 4). The results showed that all the proteins in the strawberry $b Z I P$ family contained 1-7 motifs. FvbZIP10 exhibited only one motif; additionally, all the proteins, except FvbZIP32, exhibited Motif 1. Although the proteins encoded by FvbZIP proteins contained 114-847 amino acids, the MEME diagram of the protein motif structure indicated that the clustered FvbZIP proteins had the same protein motif location and almost the same types of conserved elements. Although the functions of most of the motif elements were unknown, certain motifs were observed in specific bZIP members, suggesting that these transcription factors had specific functions. A similar finding has been reported in other species, indicating that some elements are relatively conserved evolutionarily [27]. These unknown elements may have specific functions in each subfamily, which may provide a new reference for the functional divergence among members of each subfamily.

Different combinations of exons and introns can exhibit different gene functions. The gene structure presented in Figure 4 can explain the evolutionary relationship of gene families [28]. The number of introns in the 54 FvbZIP genes of the strawberry ranged from 0 to 11 . Studies have shown that $19 \%$ of the genes in the bZIP families of sorghum and rice had no intron, and only two genes in the grape bZIP gene family had no intron. However, 11 FvbZIP genes were found to have no introns, accounting for $20 \%$ of all FvbZIP genes, which is higher than that observed in grapes, sorghum, and rice [22,26,29]. Moreover, FvbZIP genes with a similar structure were predominantly clustered together. 


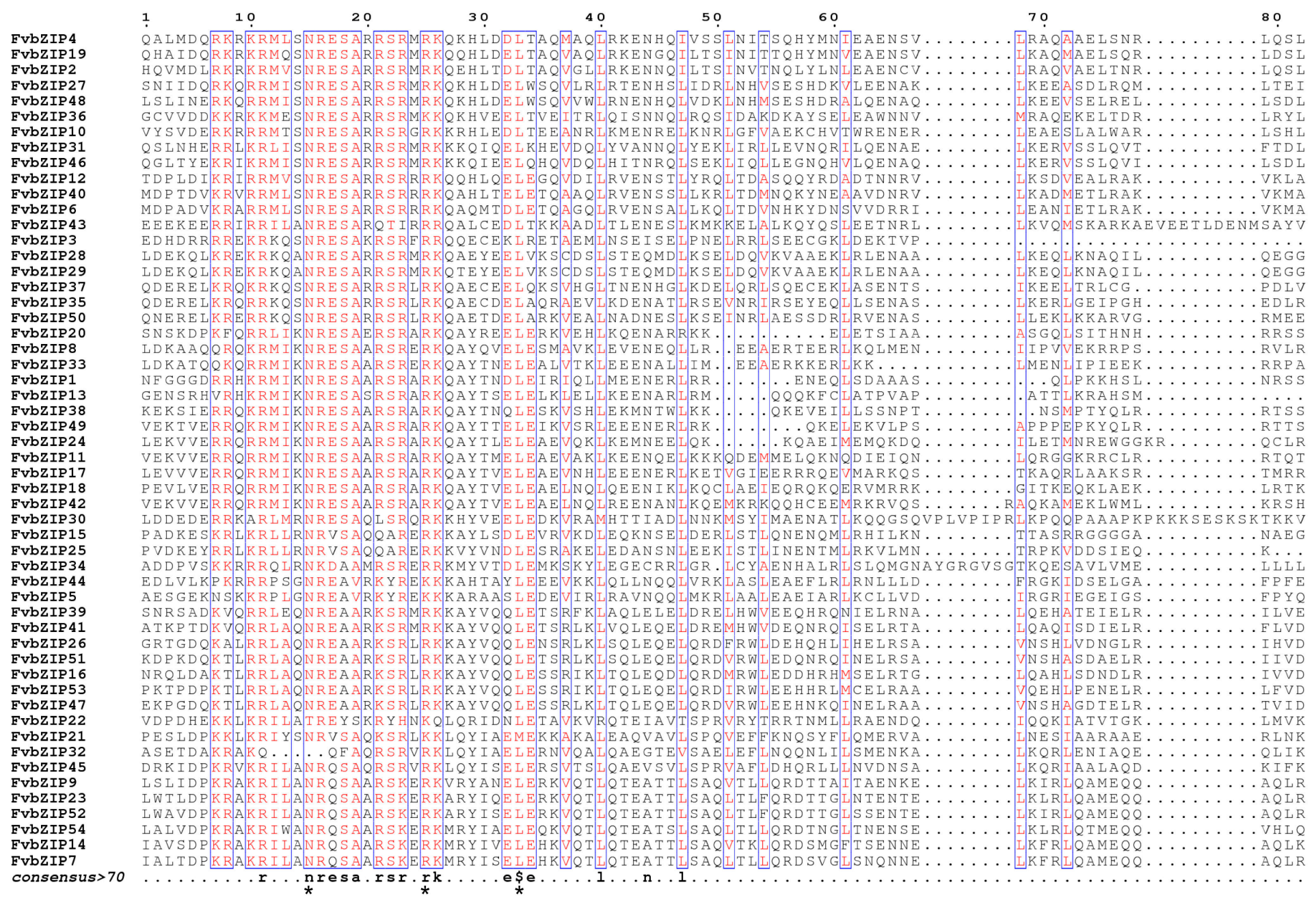

Figure 3. Multiple alignments of conserved domains of all identified FvbZIP proteins. Asterisks show the conserved amino acids of the bZIP domain. 

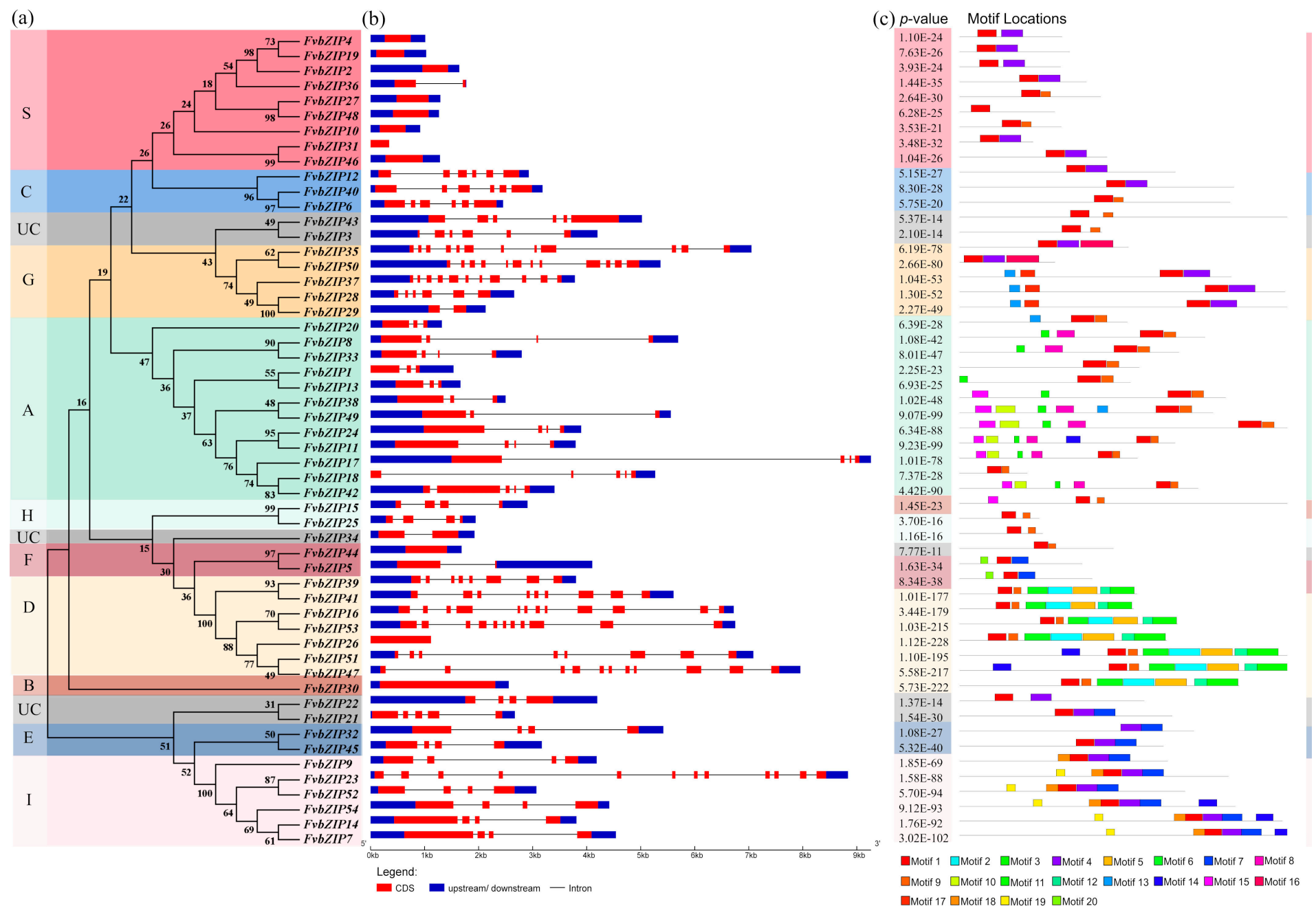

Figure 4. (a) Phylogenetic analysis of strawberry bZIP genes. The phylogenetic tree was generated using the amino acid sequences of bZIP proteins via NJ methods. All strawberry $b Z I P$ genes were classified into 10 groups. (b) Gene structure. Through the website Gene Structure Display Server, the whole genome sequence and CDS sequence of FvbZIP genes were formulated into an information map containing the structure of each FvbZIP gene. (c) Motif patterns of strawberry bZIP proteins. The protein sequence of all the strawberry bZIP proteins were entered into the MEME, with the highest motif number set to 20 and the other parameters set to the default. 


\subsection{Response of the FabZIP Genes of Fragaria $\times$ Ananassa "Benihoppe" Strawberry to Stress Caused by B. Cinerea}

Based on the bioinformatics research of FvbZIP genes in the woodland strawberry, in order to study the expression pattern of FabZIP genes in the cultivated strawberry, fluorescence quantitative detection was carried out for different development stages of strawberries and different onset stages of gray mold. Real-time fluorescence quantitative analysis was performed to collect the expression data of the 54 bZIP genes of cultivated strawberries at different developmental stages and different stages of the gray mold disease (Figure 5). The collected expression data of strawberry bZIP genes were subjected to cluster analysis, and changes in the gene expression level were compared using the cluster diagram. Most of the $54 \mathrm{bZIP}$ genes appeared to be downregulated during the developmental stages, and the trend was flat. Among them, FabZIP18, FabZIP20, FabZIP21, FabZIP22, FabZIP38, FabZIP42, and FabZIP53 were highly downregulated, and the expression level was also relatively low at the onset of gray mold disease. However, the expression of most genes was substantially upregulated after $B$. cinerea infection; only a few genes exhibited a flat expression trend before and after infection. Currently, studies have verified that some members of the $S$ and D subfamilies of bZIP transcription factors are involved in the regulation of plant growth and disease defense mechanism [30,31]. Members of the $S$ subfamily exhibited an inconsistent trend of change in expression levels. With the growth and development of the fruit, only FabZIP46 was found to be evidently upregulated, whereas the expression levels of other members remained relatively low. Members of the D subfamily, FabZIP39, FabZIP26, and FabZIP16, exhibited a relatively low expression level and a gradual upregulation trend. After infection with B. cinerea, FabZIP27, FabZIP36, and FabZIP46 of the S subfamily exhibited an apparent upregulation trend at disease onset. Among these genes, FabZIP46 maintained a relatively high expression level. The expression levels of FabZIP16, FabZIP26, FabZIP39, FabZIP47, FabZIP41, and FabZIP51 but not FabZIP 53 of the D subfamily were evidently upregulated.

From what has been discussed above, FabZIP46 was substantially upregulated, and its expression remained relatively high at different developmental stages as well as at different stages after the onset of gray mold disease. Therefore, FabZIP46 was inferred to play a role in the resistance mechanisms of the strawberry to gray mold disease.

The bZIP transcription factors used in the comparison were selected according to a previous report and included AtbZIP2, AtbZIP10, and AtTGA5 in Arabidopsis [18], CabZIP1, CabZIP2, and CcPPI1 in hot peppers [13,16,32], OsbZIP1 in rice [33], NtbZIP60 and NtTGA2.2 in tobacco [34,35], VvbZIP23 in grapes, TabZIP1 in wheat, LrbZIp1 in the lily, and SLAREB1 in tomatoes [18,36-38]. The results revealed that FabZIP46 had a high homology with LrbZIP1 and CcPPI1. The overexpression of LrbZIP1 in tobacco can significantly inhibit the growth of Fusarium oxysporum. CcPPI1 is a nuclear protein capable of activating transcription in yeast [18]. It is a transcription factor that can be part of the plant defense response against pathogen infection [32]. Therefore, the function of FabZIP46 may be similar to that of LrbZIP1 and CcPPI1 and may be related to the resistance of strawberries to gray mold disease.

\subsection{Analysis of the Transient Expression of FabZIP46 in Strawberries}

FvbZIP and AtbZIP genes are not located in independent branches. In "Benihoppe", FabZIP46 has high homology with $b Z I P$ genes related to disease resistance in other species, indicating that, although gene sequences of different species are different, the bZIP protein has similar functions in regulating signal transduction of plant biological and nonbiological stress response. Therefore, it can be concluded that the FabZIP46 gene also plays an important role in resistance to pathogenic bacteria in cultivated strawberries. FabZIP46 was cloned from "Benihoppe" by homologous cloning. To further analyze the role of FabZIP46 in the incidence of gray mold disease in strawberries, FabZIP46 in strawberries was overexpressed and silenced using the Agrobacterium-mediated transient transformation method. 


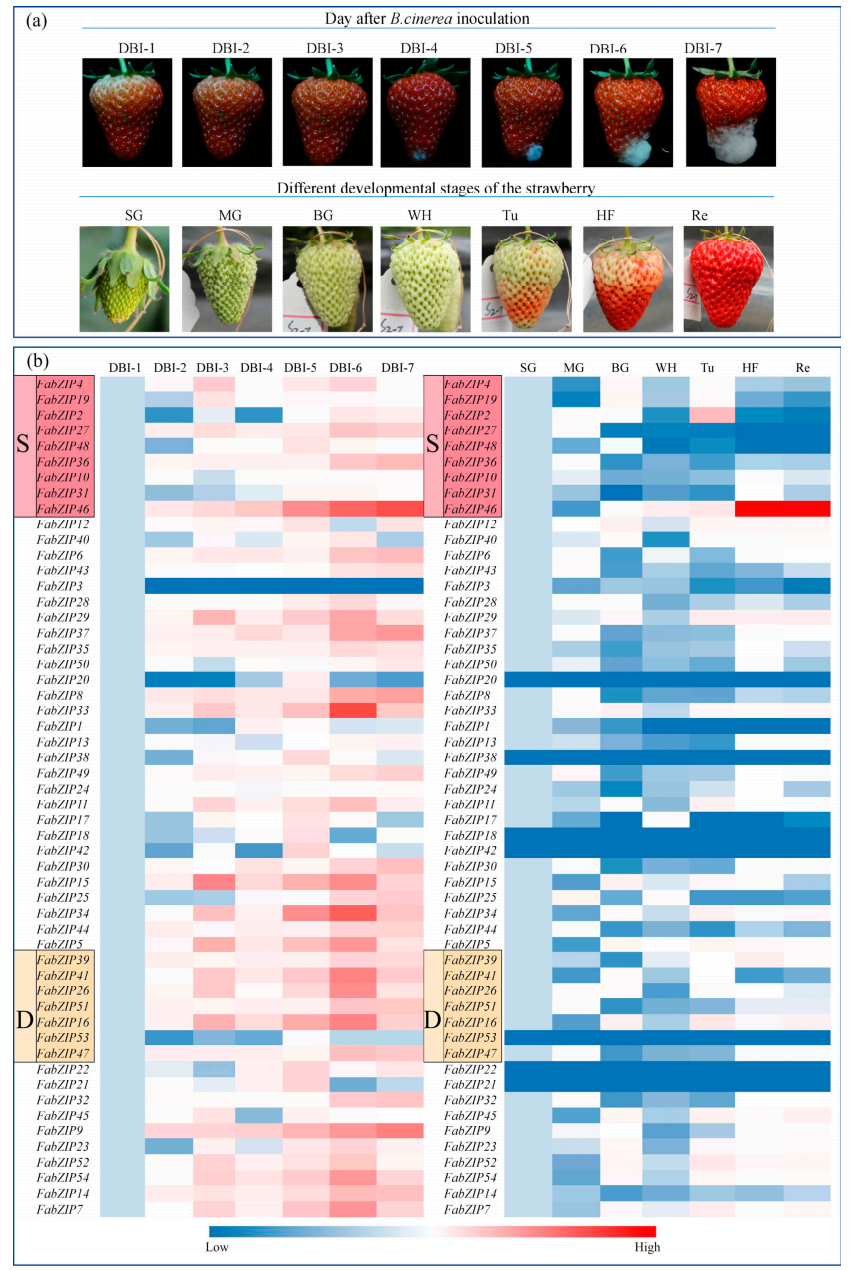

Figure 5. (a) Photographs showing the different developmental stages of strawberries. The whole process of strawberry development was divided into SG, MG, BG, Wh, Tu, HF, and Re stages. Phenotypes of red fruit after Botrytis cinerea inoculation. (b) The expression of FabZIP genes in different strawberry growth stages and in different stages after Botrytis cinerea inoculation of red fruit.

The FabZIP46 gene in strawberries was transiently overexpressed and silenced after the transient transgenic transformation (Figure 6). The results revealed that the timing of disease onset in strawberries overexpressing FabZIP46 was markedly delayed compared with that in the empty vector control. The disease incidence rate was also reduced, and the number of diseased fruits remained low even on the sixth day of $B$. cinerea inoculation. By contrast, the timing of disease onset was advanced, and the condition of the fruits was more severe after FabZIP46 silencing. The fruits injected with different vectors were compared with those inoculated with $B$. cinerea during the same period, and the statistical data revealed that the incidence rate of strawberries overexpressing FabZIP46 was substantially lower than that of the control group. Most fruits had only small lesions, and almost no fruit had severe lesions on the sixth day after injection. By contrast, the disease incidence rate of the fruits was higher than that of the control group after FabZIP46 was silenced. The results revealed that nearly all fruits were diseased on the sixth day after injection, and severely affected fruits accounted for more than half of the total fruit (Table S2). The results suggested that overexpression of FabZIP46 increases the resistance of strawberries; it not only delayed the onset timing of gray mold disease in strawberries but also reduced the incidence rate. Moreover, the disease onset condition in fruit with silenced FabZIP46 was not apparently different from that in the control group. The experimental results indicated that FabZIP46 played a role in the resistance of strawberries to gray mold disease. 

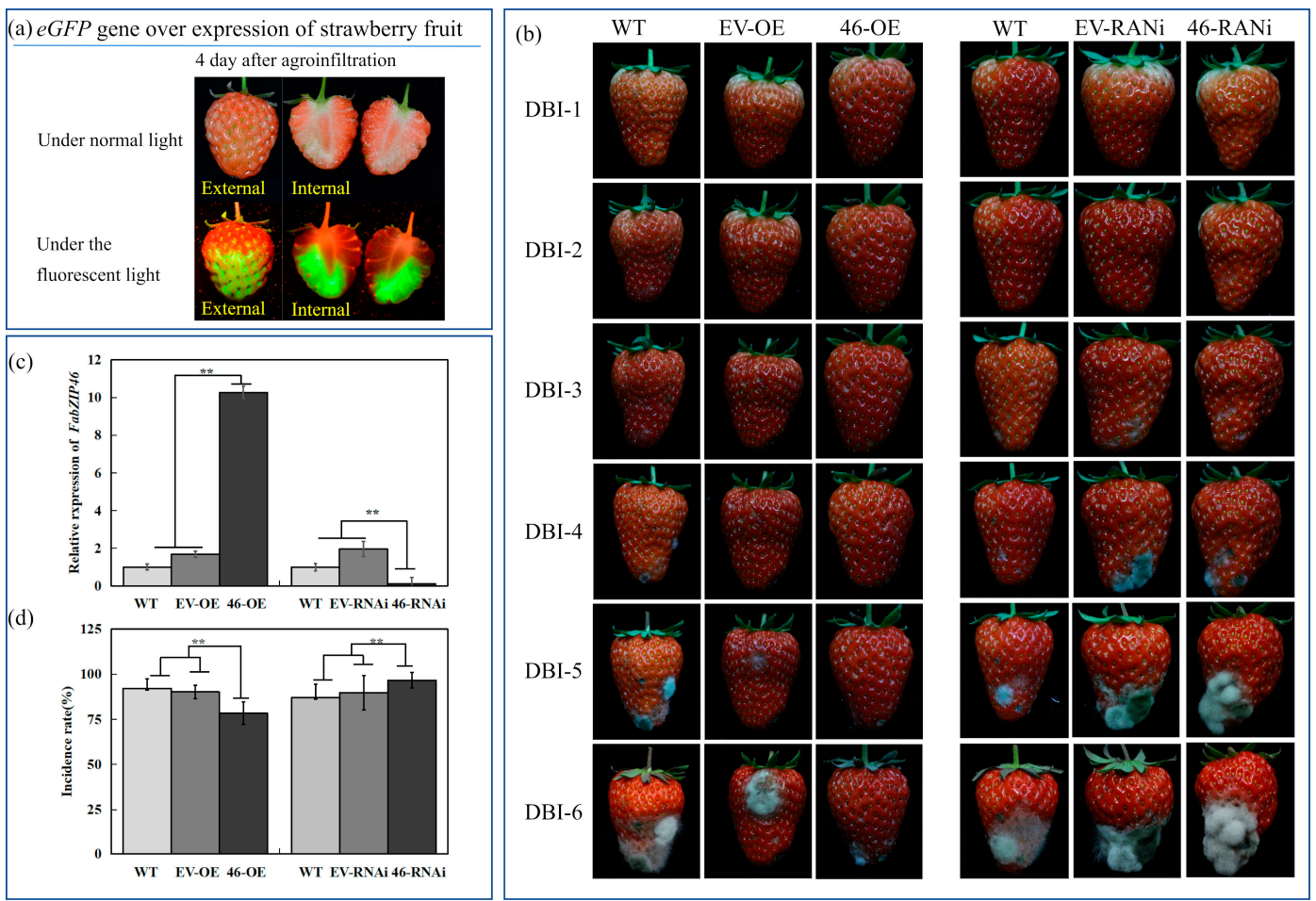

Figure 6. (a) Manipulated FabZIP46 gene expression levels in strawberries, obtained using transient overexpression and gene silencing techniques. Green fluorescence emitted by transformed strawberries was detected at four days after injection, indicating that the FabZIP46 gene was overexpressed or silenced in strawberries. (b) Phenotypes of FabZIP46-OE and FabZIP46-RNAi strawberries after Agrobacterium tumefaciens injection and Botrytis cinerea inoculation. Strawberries at the red stage of development were injected with A. tumefaciens, and B. cinerea inoculation was performed four days after $A$. tumefaciens injection. To avoid tissue damage that might affect the experimental results, approximately $1 \mathrm{~mL}$ (depending on the fruit size) of $A$. tumefaciens suspension was evenly injected into the fruits through the pedicel with a sterile hypodermic syringe. The injection depth was approximately half of the longitudinal diameter of the fruit to ensure that the A. tumefaciens suspension was fully released in the pith of the fruit. The first vertical line, second vertical line, fourth vertical line, and fifth vertical line represent the phenotypes of non-transgenic control fruits and transgenic fruits with empty vectors. The third vertical line and sixth vertical line show the phenotypes of transgenic fruits with FabZIP46-OE and FabZIP46-RNAi, respectively. (c) Changes in relative FabZIP46 gene expression levels in FabZIP46-OE and FabZIP46-RNAi fruits. Values are means $\pm \mathrm{SD}(n \geq 3)$. Asterisks above the columns denote a significant difference at ${ }^{* *} p<0.05$ levels according to the Student's $t$-test. (d) Comparison of the incidence of FabZIP46-OE and FabZIP46-RNAi in strawberries after Botrytis cinerea inoculation.

\subsection{Effect of Overexpression and Silencing of FabZIP46 on the Expression of Disease-Resistant Genes}

In order to explore the molecular mechanism of FabZIP46 in resistance to gray mold in strawberries, some genes related to resistance reported in the literature were selected for expression detection. Transcription factors are closely related to plant disease resistance. In this experiment, FaWRKY1, FaWRKY33, and FaWRKY70 related genes in the WRKY transcription factor family identified from the disease resistance correlation in plants were selected [39-41]. FaWRKY1, FaWRKY33, and FaWRKY70 were evidently regulated when FabZIP46 was overexpressed or silenced. When FabZIP46 was overexpressed, the expression of FaWRKY1 and FaWRKY70 was positively regulated and that of FaWRKY33 was negatively regulated (Figure 7). 


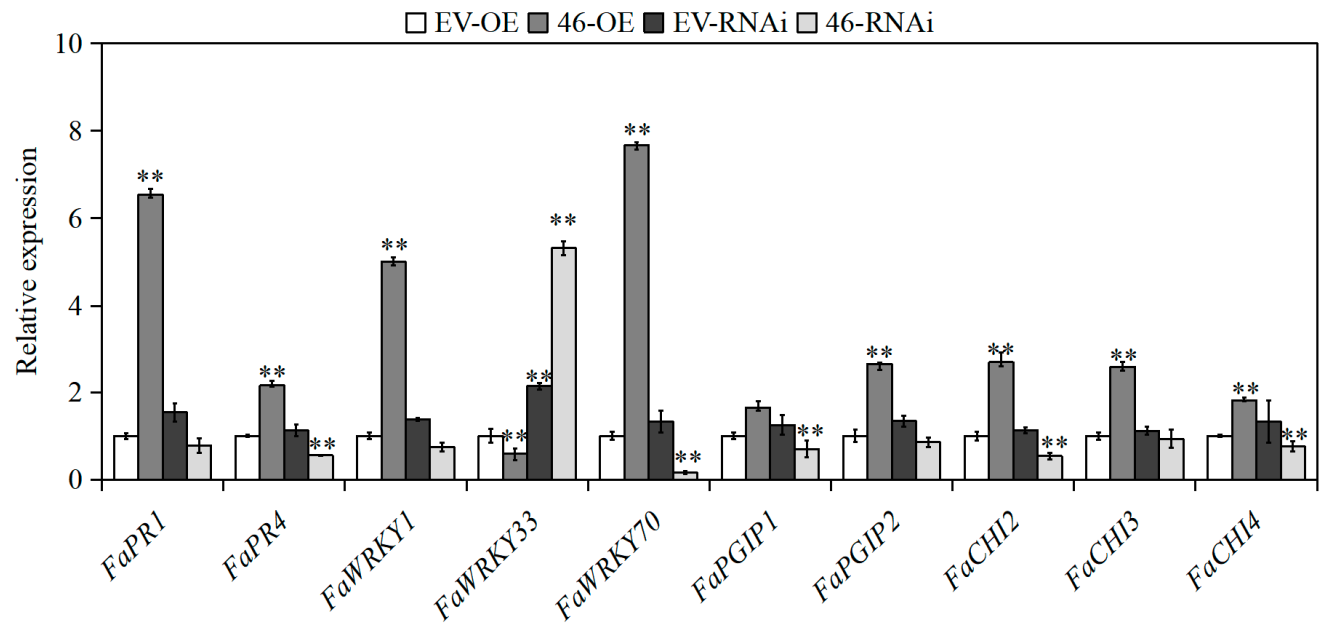

Figure 7. Effects of FabZIP46-OE and FabZIP46-RNAi on the transcription of resistance-related genes. $E V-O E$ and $E V-R N A i$ denote controls for the overexpressed or silenced fruits transformed with the corresponding empty vector. Values are means $\pm \mathrm{SD}(n \geq 3)$. Asterisks above the columns denote significant difference at ${ }^{* *} p<0.05$ levels according to the Student's $t$-test.

In addition, polygalacturonase-inhibiting proteins (PGIP) and chitinase (CHI) play defensive roles in the disease resistance of strawberries in the plant immune system [42,43]. The pathogenesis-related proteins (PR) also play an important role in the pathogenesis and necrosis of plants [44]. Therefore, FaPR1, FaPR4, FaCHI2, FaCHI3, FaCHI4, FaPGIP1, and FaPGIP2 were selected for gene expression detection. The results showed that the expression levels of most of these defense genes were also regulated to varying degrees, of which FaPR1 was strongly regulated.

\section{Discussion}

Numerous studies have indicated that members of the bZIP gene family play a role in plant growth and development and respond to biotic and abiotic stresses [45]. Presently, genes related to the bZIP gene family members have been extensively identified in Arabidopsis, rice, and other model plants $[46,47]$. Therefore, the role of $b Z I P$ genes in strawberries was investigated through a bioinformatic analysis. A total of 54 bZIP genes of the strawberry were identified in this study, which was less than the number of $b Z I P$ genes in Arabidopsis thaliana. By using the results of cluster analysis on $b Z I P$ gene members of Arabidopsis and rice, the $b Z I P$ gene members of strawberries were classified into 10 subfamilies. To date, several studies on bZIP transcription factors in plants have demonstrated that different subfamilies control various transcriptional regulation pathways in different plants. Among them, $b Z I P$ genes of subfamily A are involved in the ABA and stress regulatory network of seeds and plant tissues [11,48]; $b$ ZIP genes of subfamily $C$ regulate protein storage in the seeds, environment and disease defense, and stress response [49,50]; and bZIP genes of subfamily $\mathrm{D}$ participate in the plant disease defense and physiological growth process [48,51,52]. Studies on the function of $b Z I P$ genes of subfamily $E$ are relatively rare, and no functional data are available for members of group E [21]. bZIP genes of subfamily $\mathrm{G}$ regulate light-regulated signal transduction and seed maturation $[53,54]$. bZIP genes of subfamily $\mathrm{H}$ play an indispensable role in light morphogenesis and light signal transduction and are required for the induction of key enzymes and nitrates in nitrogen assimilation [55]. bZIP genes of subfamily I play a critical role in the vascular development of plants [56]. Finally, as a comparatively large group, bZIP genes of subfamily $S$ play a vital role in disease defense and stress response [57]. Studies on some subfamilies, such as B and F, have not been reported, so further research is required to explore their functions.

Wang et al. analyzed the evolutionary patterns of the homologous $b Z I P$ genes in strawberries, apples, and peaches [58]. By analyzing the evolution of $b Z I P$ genes in three species of Rosaceae, it is shown that many $b Z I P$ genes are produced by gene replication. The FvbZIP genes were found to have 
undergone a dramatic evolutionary diversification, with protein sequence similarities ranging from $9 \%$ to $100 \%$. In the present study, bZIP proteins from three different plant species were divided into 10 groups, with each group containing at least one AtbZIP or OsbZIP, indicating the conservation of $b Z I P$ genes in different plants. This suggests that FvbZIP genes share some common ancestor genes with those of other plants. The phylogenetic tree constructed with the proteins of strawberries, Arabidopsis, and rice showed that most of the FvbZIP genes were more closely related to Arabidopsis. This uggests that the evolution of the strawberry $b Z I P$ gene family is comparatively conserved and these genes may have functions similar to those of Arabidopsis homologous genes. Through chromosomal localization, 54 FvbZIP genes were found to be unevenly distributed on seven chromosomes, among which FvbZIP53 and FvbZIP54 could not be located on the chromosome. The analysis of gene structure revealed that members of the same strawberry bZIP subfamily were found to have the same or similar genetic structures, particularly the number and length of exons, indicating that the classification in this study is accurate. The above results indicate that genes in the strawberry bZIP gene family are highly conserved in structure, and their function and characteristics are similar to those of Arabidopsis bZIP genes. This finding may serve as a reference for the future application of genetic engineering and genetic analysis to verify the function of bZIP gene family in strawberries.

The diploid woodland strawberry is not widely cultivated in the strawberry production industry. At present, the main edible strawberry is the octoploid strawberry, so this experiment used "Benihoppe" as the research object. The results of real-time fluorescence quantitative analysis on the expression of the 54 strawberry bZIP transcription factors at different developmental stages of the fruits and different stages of gray mold disease showed that FabZIP46 was substantially upregulated both with the fruit growth and development and with the onset of gray mold disease, and the expression was maintained at a relatively high level. In addition, a phylogenetic tree was constructed by comparing the protein sequences of FabZIP46 and those of bZIP transcription factors to investigate disease resistance in various species. According to previous reports, $b Z I P$ genes related to the disease resistance of different species such as tobacco, Arabidopsis, rice, peppers, and tomatoes were selected for homology comparison with FabZIP46 (Figure S2). The results revealed that FabZIP46 had a high homology with LrbZIP1 and CCPPI1. Therefore, the function of FabZIP46 may be similar to that of LrbZIP1 and CcPPI1 and may be related to the resistance of strawberries to gray mold disease.

bZIP transcription factors are known to be related to abiotic and biotic stress responses. Presently, numerous bZIP transcription factors with specific functions in plants have been identified. Studies have shown that overexpressing or silencing $b Z I P$ genes may enhance the resistance of plants to abiotic and biotic stresses. Silencing the CabZIP2 gene in hot peppers results in disease-susceptible traits, and overexpression CabZIP2 in Arabidopsis enhances their resistance to Pseudomonas syringae pv. Tomato [16]. Overexpressing NtTGA2.2 in tobacco may enhance the expression of early genes $P R 1-a$ and ParA, but the expression of early genes could not be induced in SA-treated mutant plants, indicating that NtTGA2.2 plays a positive regulatory role in pathogen defense [59]. The results of the above studies indicate that $b$ ZIP genes in cultivated strawberries may also have a similar function of defense against pathogenic bacteria. The disease onset in strawberries overexpressing FabZIP46 was evidently delayed compared with the control group; the incidence rate was also decreased. By contrast, the disease incidence was severe in fruit after FabZIP46 silencing, and the incidence rate exceeded 50\% on the fourth day. Most functional verification studies of $b Z I P$ genes have been conducted in the model plant Arabidopsis. However, the plant characteristics of Arabidopsis are considerably different from those of cultivated strawberries. To date, no study has investigated the role of FabZIP46 in strawberry gray mold disease. Therefore, further investigations are required to reveal the specific role of $b Z I P$ genes in strawberries.

A study of transcription factors involved in disease resistance revealed that the expression level of three genes in the WRKY transcription factor family, FaWRKY1, FaWRKY33, and FaWRKY70, were significantly changed when FabZIP46 was overexpressed or silenced. Therefore, it can be 
speculated that $b Z I P$ can interact with WRKY transcription factor and play an important role in the plant response to biotic and abiotic stress and various signaling pathways.

Polygalacturonase-inhibiting proteins (PGIP) and chitinase (CHI) play a defensive role in strawberries [42,43]; pathogenesis-related proteins (PR) also play a critical role in the pathogenesis of plant necrosis [44]. In this study, FaPR1, FaPR4, FaCHI2, FaCHI3, FaCHI4, FaPGIP1, and FaPGIP2 were selected for gene expression detection. The results revealed that the regulation of the expression of these defense-related genes was varied, and FaPR1 was highly regulated. This finding indicates that the plant defense response may have multiple underlying defense mechanisms. FabZIP46 is likely to strengthen the defense of strawberries against $B$. cinerea and delay the onset of gray mold disease by upregulating PR and PGIP genes.

In summary, 54 strawberry $b Z I P$ gene family members were predicted by adopting the bioinformatics approach, and a cluster analysis was conducted using the Arabidopsis bZIP gene family. Bioinformatics data, including domain, gene structure, chromosome distribution, and the distribution of conserved elements, indicated that these genes are relatively conserved during evolution and may play a key role in the stress response to gray mold disease. The study results provide insights into the function of the strawberry FvbZIP protein family and may be used as a reference for screening genes related to disease resistance through genetic engineering. The cluster analysis of data from real-time fluorescence quantitative experiment was used to predict that FabZIP46 is related to the resistance mechanism of strawberries to gray mold disease, and its function was verified using a transient transformation experiment. The results revealed that FabZIP46 positively regulated the resistance of strawberries to gray mold disease.

\section{Materials and Methods}

\subsection{Fungi and Plant Materials}

The B. cinerea used in this study was isolated from infected plants in a strawberry planting base of Jiangsu Agricultural Expo Garden by the Jiangsu Horticultural Modern Technology Engineering Center. After conventional purification treatments, the isolated B. cinerea was inoculated on potato dextrose agar (PDA) and cultured at $25^{\circ} \mathrm{C}$ for 14 days. After four weeks of culture, the mycelium was scraped from the surface of the strain, and the spores of $B$. cinerea were diluted with sterile water into a spore suspension (containing $0.01 \%(v / v)$ Tween-20) at a concentration of $1 \times 10^{5}$ spores $/ \mathrm{mL}$ for fruit inoculation.

The test plant, the octoploid cultivar "Benihoppe" strawberry, was picked from the strawberry planting base of Jiangsu Agricultural Expo Garden between December 2019 and February 2020. The fruits were uniform in size and shape, with no deformities.

Based on a previous study, the development of strawberries was divided into seven stages according to the local environmental conditions for cultivation [60]: small green fruit (SG, 20-25 d postflowering), medium green fruit (MG, 28-33 d postflowering), large green fruit (BG, 35-40 d postflowering), white fruit (Wh, $40-45 \mathrm{~d}$ postflowering), color-turning fruit ( $\mathrm{Tu}, 45-50 \mathrm{~d}$ postflowering), half-red fruit (HF, $48-53 \mathrm{~d}$ postflowering), and red fruit (Re, 50-55 d postflowering). Ten strawberries at each developmental stage were collected from the field. After the seeds were removed from the surface, the fruits were rapidly frozen with liquid nitrogen and stored in a refrigerator at $-80^{\circ} \mathrm{C}$. The expression levels of FvbZIP genes were detected in these strawberry samples at different developmental stages. The experiment was repeated three times.

\subsection{Extraction of FvbZIP Genes from Strawberries and Prediction of Physicochemical Properties}

By using the conserved structural domain PF000170 of bZIP as a probe, the whole genome sequence and CDS sequence of $b Z I P$ genes in the strawberry were collected from the database of the National Center for Bioinformatics (https://www.ncbi.nlm.nih.gov). The structures of the downloaded FvbZIP proteins were predicted using NCBI-CDD. Proteins that did not include the bZIP structural domain 
were deleted. In addition, the molecular weight and isoelectric point of the amino acid sequence of all bZIP proteins were predicted using the online tool ProtParam (http://web.expasy.org/protparam/), and the subcellular localization of all bZIP proteins were predicted using the online tool Cell-PLoc-2.0 (http://www.csbio.sjtu.edu.cn/bioinf/Cell-PLoc-2/).

\subsection{Phylogenetic Analysis and Sequence Alignment of Strawberry FvbZIP Genes}

The amino acid sequences of Arabidopsis bZIP proteins were downloaded from the Arabidopsis Information Resource (TAIR, https://www.arabidopsis.org/), and those of rice were downloaded from RiceData (https://www.ricedata.cn/gene). Multiple sequence alignment was conducted to compare the protein sequence of the downloaded protein and that of the predicted FvbZIP proteins by using ClustalX2.0 (http://www.clustal.org/clustal2/). All the parameters were set to the default. The result of the sequence alignment was imported to MEGA7.0 (http://www.megasoftware.net/history.php) to plot a phylogenetic tree by using the neighbor-joining method. Additionally, an independent phylogenetic tree was constructed with the complete FvbZIP protein sequences. The execution parameters were set as follows: mode: "Poisson correction" gap setting: "Complete Deletion" validation parameter: Bootstrap $=1000$, and random seeds. The gene mapping information of FvbZIP genes was obtained from the NCBI database, and a chromosome mapping graph was plotted using the online software MapGene2Chromosome2 (http://mg2c.iask.in/mg2c_v2.0/).

\subsection{Analysis of the Structure of FvbZIP Genes in the Strawberry and Analysis of the MEME Protein Motif}

Through the website Gene Structure Display Server (http://gsds.gao-lab.org/), the whole genome sequence and CDS sequence of FvbZIP genes were formulated into an information map containing the structure of each FvbZIP gene. Moreover, the structures of the conserved domain and other protein motifs of strawberry FvbZIP proteins were analyzed. The protein sequence of all the strawberry bZIP proteins were entered into the website, with the highest motif number set to 20 and the other parameters set to the default (http://meme-suite.org/tools/meme).

\subsection{Real-Time Fluorescence Quantitative Analysis of Gene Expression}

All the reagents required for real-time fluorescence quantitation were provided by, and primer synthesis (Table S3) was conducted by, TAKARA Bio., Inc. (http://www.takara.com.cn/). A total RNA extraction kit was used to extract total RNA from strawberries, and M-MLV reverse transcriptase was used to synthesize cDNA. Quantitative RT-PCR was performed using SYBR PreMix, and the internal reference gene was FaACTIN. The relative expression level of the genes was calculated using the $2^{-\Delta \Delta C T}$ method. The experiment was biologically duplicated three times.

\subsection{Gene Cloning and Vector Construction}

Referring to the information of FvbZIP46 published by NCBI (GenBank accession number: XM_011468884.1), the full-length FabZIP46 gene was obtained from "Benihoppe" strawberries by homologous cloning. Full-length FabZIP46 contained 691 bp, encoding 230 amino acids. The vector was constructed using Gateway technology. After verification of the sequence, the cloned fragment was inserted into the TOPO vector (TOPO PCR Cloning technology; Thermo Fisher Scientific Inc., Shanghai, China). Subsequently, an LR reaction between the TOPO vector and the target expression vector of the plant pH7WG2D was conducted to generate 35S::FabZIP46 to obtain a FabZIP46 overexpression vector (overexpression vector FabZIP46, FabZIP46-OE). The LR reaction is a recombination reaction between an attL entry clone and an attR destination vector. The LR reaction is used to transfer the destination sequence to one or more destination vectors in parallel reactions. The empty vector pH7WG2D (EV-OE) was used as control. The plant expression vector pH7WG2D was constructed to contain a green fluorescent protein-encoding $(e-G F P)$ gene to facilitate further detection. Under a stereoscopic fluorescence microscope, the green fluorescence emitted by successfully transformed 
strawberries can be directly observed, whereas no green fluorescence can be detected in unsuccessfully transformed strawberries.

For the transient silencing of FabZIP46 in strawberries, a hairpin structure of FabZIP46, pFGC5941:FabZIP46:RNAi was constructed using pFGC5941. pFGC5941 is a widely used vector for RNA interference of plant genes. Next, FabZIP46:RNA $i$ was amplified using a specifier, and the product was subjected to the LR reaction along with the target vector $\mathrm{PH7WG2D}$ to generate a FabZIP46::RNAi silencing/expression vector (RNAi-expression vector FabZIP46, FabZIP46-RNAi). The empty vector pH7WG2D (EV-RNAi) was used as a control.

All vectors were transformed into Agrobacterium GV3101 by using a freeze-thaw method for subsequent transient transformation of strawberries. All the amplified sequences and specifiers used for vector construction are given in Table S3.

\subsection{Transient Transformation of Strawberries and Experimental Design}

Non-diseased strawberries that were at the stage of turning from white to red and growing on healthy plants were picked from the field. After sterilization, the fruits were placed in a confined space at a temperature of $25^{\circ} \mathrm{C}$ and a relative humidity of $85 \%$. Using a 1-mL syringe, a single dose of $1 \mathrm{~mL}$ of the prepared bacterial injection solution was injected into the hollow pith of the strawberry through the fruit stalk. The injection volume of the Agrobacterium suspension was moderately adjusted according to the size of the fruit to ensure that the bacterial solution completely infected the fruit. A total of 200 fruits were injected with each bacterial carrier suspension, and changes in the fruit were observed and recorded daily after the injection. The vectors used in the transient transformation study carried the green fluorescent protein gene (eGFP) with extremely strong expression. Therefore, once successfully transformed, fluorescence was observed in the fruit by using the fluorescence observation system on the second day after injection of bacterial suspension. The fluorescence intensity reached the maximum on the fifth day. On the fourth day after injection and after the fluorescence became observable, three samples were selected from each group to examine the expression level of FabZIP46. Subsequently, 150 fruits that exhibited fluorescence were selected from each group for B. cinerea inoculation. Holes were pricked on the surface of the selected fruits and B. cinerea was inoculated onto the pricked sites to observe the disease incidence. After inoculation with B. cinerea, three samples were taken every $24 \mathrm{~h}$ to detect the expression level of related genes; the samples were taken six consecutive times. The remaining 132 strawberries were used for statistical analysis of disease incidence. The experiment was repeated three times in the fruiting stage of strawberries. The majority of the strawberries were photographed to record the disease progression during the experiment.

Supplementary Materials: The following are available online at http://www.mdpi.com/2223-7747/9/9/1199/s1, Table S1: Related information of strawberry bZIP gene family, Table S2: Incidence of strawberries after B. cinerea inoculation, Table S3: Primer sequences used for qRT-PCR in this study, Figure S1: The conserved domain logo of the FvbZIP genes, AtbZIP genes and OsbZIP genes, Figure S2: Phylogenetic tree of disease-resistant $b Z I P$ genes from different plants.

Author Contributions: Conceptualization, B.L. and Y.W.; methodology, B.L., Y.W. and G.Z.; analysis, B.L., Y.F., and Z.Y.; writing—original draft preparation, B.L. and Y.W.; supervision and project administration, J.W. and X.C.; funding acquisition, J.W. and Y.W. All authors have read and agreed to the published version of the manuscript.

Funding: This work was supported by the National Natural Science Foundation of China (31701898), the Natural Science Foundation of Jiangsu Province, China (BK20160567), the Science Fund of Jiangsu Vocational College of Agriculture and Forestry (2017kj06; 2019kj011), the Six Talent Peaks Project in Jiangsu Province (NY-019, NY-156), and the Blue Project of Jiangsu Province.

Conflicts of Interest: The authors declare no conflict of interest. 


\section{References}

1. Kumar, R.; Khurana, A.; Sharma, A.K. Role of plant hormones and their interplay in development and ripening of fleshy fruits. J. Exp. Bot. 2014, 65, 4561-4575. [CrossRef]

2. Symons, G.M.; Chua, Y.J.; Ross, J.J.; Quittenden, L.J.; Davies, N.W.; Reid, J.B. Hormonal changes during non-climacteric ripening in strawberry. J. Exp. Bot. 2012, 63, 4741-4750. [CrossRef]

3. Amselem, J.; Cuomo, C.A.; Van Kan, J.A.; Viaud, M.; Benito, E.P.; Couloux, A.; Coutinho, P.M.; de Vries, R.P.; Dyer, P.S.; Fillinger, S.; et al. Genomic analysis of the necrotrophic fungal pathogens Sclerotinia sclerotiorum and Botrytis cinerea. PLoS Genet. 2011, 7, e1002230. [CrossRef]

4. Williamson, B.; Tudzynski, B.; Tudzynski, P.; Van Kan, J.A. Botrytis cinerea: The cause of grey mould disease. Mol. Plant Pathol. 2007, 8, 561-580. [CrossRef]

5. Dean, R.; Van Kan, J.A.; Pretorius, Z.A.; Hammond, K.E.; Di Pietro, A.; Spanu, P.D.; Rudd, J.J.; Dickman, M.; Kahmann, R.; Ellis, J.; et al. The Top 10 fungal pathogens in molecular plant pathology. Mol. Plant Pathol. 2012, 13, 414-430. [CrossRef]

6. Bestfleisch, M.; Ludererpflimpfl, M.; Hofer, M.; Schulte, E.; Wunsche, J.; Hanke, M.; Flachowsky, H. Evaluation of strawberry (Fragaria L.) genetic resources for resistance to Botrytis cinerea. Plant Physiol. 2015, 64, 396-405.

7. Windram, O.; Madhou, P.; McHattie, S.; Hill, C.; Hickman, R.; Cooke, E.; Jenkins, D.J.; Penfold, C.A.; Baxter, L.; Breeze, E.; et al. Arabidopsis defense against Botrytis cinerea: Chronology and regulation deciphered by high-resolution temporal transcriptomic analysis. Plant Cell 2012, 24, 3530-3557. [CrossRef]

8. Pandey, D.; Rajendran, S.R.C.K.; Gaur, M.; Sajeesh, P.K.; Kumar, A. Plant defense signaling and responses against necrotrophic fungal pathogens. J. Plant Growth Regul. 2016, 35, 1159-1174. [CrossRef]

9. Wei, K.; Chen, J.; Wang, Y.; Chen, Y.; Chen, S.; Lin, Y.; Pan, S.; Zhong, X.; Xie, D. Genome-wide analysis of bZIP-encoding genes in maize. DNA Res. 2012, 19, 463-476. [CrossRef]

10. Smykowski, A.; Zimmermann, P.; Zentgraf, U. G-Box binding factor1 reduces CATALASE2 expression and regulates the onset of leaf senescence in Arabidopsis. Plant Physiol. 2010, 153, 1321-1331. [CrossRef]

11. Choi, H.; Hong, J.; Ha, J.; Kang, J.; Kim, S.Y. ABFs, a family of ABA responsive element binding factors. J. Biol. Chem. 2000, 275, 1723-1730. [CrossRef] [PubMed]

12. Baena-González, E.; Rolland, F.; Thevelein, J.M.; Sheen, J. A central integrator of transcription networks in plant stress and energy signalling. Nature 2007, 448, 938-942. [CrossRef] [PubMed]

13. Lim, C.W.; Baek, W.; Lim, S.; Han, S.W.; Lee, S.C. Expression and Functional Roles of the Pepper Pathogen-Induced bZIP Transcription Factor CabZIP2 in Enhanced Disease Resistance to Bacterial Pathogen Infection. Mol. Plant Microbe Interact. 2015, 28, 825-833. [CrossRef] [PubMed]

14. Fu, J.; Wu, H.; Ma, S.; Xiang, D.; Liu, R.; Xiong, L. OsJAZ1 Attenuates Drought Resistance by Regulating JA and ABA Signaling in Rice. Front. Plant Sci. 2017, 8, 2108. [CrossRef]

15. Ma, H.; Liu, C.; Li, Z.; Ran, Q.; Xie, G.; Wang, B.; Fang, S.; Chu, J.; Zhang, J. ZmbZIP4 Contributes to Stress Resistance in Maize by Regulating ABA Synthesis and Root Development. Plant Physiol. 2018, 178, 753-770. [CrossRef]

16. Lee, S.C.; Choi, H.W.; Hwang, I.S.; Choi, D.S.; Hwang, B.K. Functional roles of the pepper pathogen-induced bZIP transcription factor, CAbZIP1, in enhanced resistance to pathogen infection and environmental stresses. Planta 2006, 224, 1209-1225. [CrossRef]

17. Liu, C.; Mao, B.; Ou, S.; Wang, W.; Liu, L.; Wu, Y.; Chu, C.; Wang, X. OsbZIP71, a bZIP transcription factor, confers salinity and drought tolerance in rice. Plant Mol. Biol. 2014, 84, 19-36. [CrossRef]

18. Zhang, N.; Liu, D.; Zheng, W.; He, H.; Ji, B.; Han, Q. A bzip transcription factor, LrbZIP1, is involved in lilium regale wilson defense responses against fusarium oxysporum f. sp. lilii. Genes Genom. 2014, 36, 789-798. [CrossRef]

19. Wang, X.L.; Chen, X.; Yang, T.B.; Cheng, Q.; Cheng, Z.M. Genome-Wide Identification of bZIP Family Genes Involved in Drought and Heat Stresses in Strawberry (Fragaria vesca). Int. J. Genom. 2017, 2017, 3981031.

20. Zhang, T.; Lv, W.; Zhang, H.; Ma, L.; Li, P.; Ge, L.; Li, G. Genome-wide analysis of the basic Helix-Loop-Helix (bHLH) transcription factor family in maize. BMC Plant Biol. 2018, 18, 235. [CrossRef]

21. Jakoby, M.; Weisshaar, B.; Dröge-Laser, W.; Vicente-Carbajosa, J.; Tiedemann, J.; Kroj, T.; Parcy, F. bZIP transcription factors in Arabidopsis. Trends Plant Sci. 2002, 7, 106-111. [CrossRef] 
22. Liu, J.; Chen, N.; Chen, F.; Cai, B.; Dal Santo, S.; Tornielli, G.B.; Pezzotti, M.; Cheng, Z.M. Genome-wide analysis and expression profile of the bZIP transcription factor gene family in grapevine (Vitis vinifera). BMC Genom. 2014, 15, 281. [CrossRef]

23. Li, Y.Y.; Meng, D.; Li, M.; Cheng, L. Genome-wide identification and expression analysis of the bzip gene family in apple (malus domestica). Tree Genet Genomes 2016, 12, 82. [CrossRef]

24. Sibéril, Y.; Doireau, P.; Gantet, P. Plant bZIP G-box binding factors. Modular structure and activation mechanisms. Eur. J. Biochem. 2001, 268, 5655-5666. [CrossRef]

25. Cyrek, M.; Fedak, H.; Ciesielski, A.; Guo, Y.; Sliwa, A.; Brzezniak, L.; Krzyczmonik, K.; Pietras, Z.; Kaczanowski, S.; Liu, F.; et al. Seed Dormancy in Arabidopsis Is Controlled by Alternative Polyadenylation of DOG1. Plant Physiol. 2016, 170, 947-955. [CrossRef]

26. Nijhawan, A.; Jain, M.; Tyagi, A.K.; Khurana, J.P. Genomic survey and gene expression analysis of the basic leucine zipper transcription factor family in rice. Plant Physiol. 2008, 146, 333-350. [CrossRef]

27. Rong, S.; Wu, Z.; Cheng, Z.; Zhang, S.; Liu, H.; Huang, Q. Genome-Wide Identification, Evolutionary Patterns, and Expression Analysis of bZIP Gene Family in Olive (Olea europaea L.). Genes 2020, 11, 510. [CrossRef]

28. Li, X.; Duan, X.; Jiang, H.; Sun, Y.; Tang, Y.; Yuan, Z.; Guo, J.; Liang, W.; Chen, L.; Yin, J.; et al. Genome-wide analysis of basic/helix-loop-helix transcription factor family in rice and Arabidopsis. Plant Physiol. 2006, 141, 1167-1184. [CrossRef]

29. Wang, J.; Zhou, J.; Zhang, B.; Vanitha, J.; Ramachandran, S.; Jiang, S.Y. Genome-wide expansion and expression divergence of the basic leucine zipper transcription factors in higher plants with an emphasis on sorghum. J. Integr. Plant Biol. 2011, 53, 212-231. [CrossRef]

30. Crawford, N.M.; Glass, A.D.M. Molecular and physiological aspects of nitrate uptake in plants. Trends Plant Sci. 1998, 3, 389-395. [CrossRef]

31. Büttner, M.; Singh, K.B. Arabidopsis thaliana ethylene-responsive element binding protein (AtEBP), an ethylene-inducible, GCC box DNA-binding protein interacts with an ocs element binding protein. Proc. Natl. Acad. Sci. USA 1997, 94, 5961-5966. [CrossRef]

32. Lee, S.J.; Lee, M.Y.; Yi, S.Y.; Oh, S.K.; Choi, S.H.; Her, N.H.; Choi, D.; Min, B.W.; Yang, S.G.; Harn, C.H. PPI1: A novel pathogen-induced basic region-leucine zipper (bzip) transcription factor from pepper. Mol. Plant Microbe Interact. 2002, 15, 540-548. [CrossRef]

33. Meng, X.B.; Zhao, W.S.; Lin, R.M.; Wang, M.; Peng, Y.L. Identification of a novel rice bzip-type transcription factor gene, osbzip1, involved in response to infection ofmagnaporthe grisea. Plant Mol. Biol. Rep. 2005, 23, 301-302. [CrossRef]

34. Tateda, C.; Ozaki, R.; Onodera, Y.; Takahashi, Y.; Yamaguchi, K.; Berberich, T.; Koizumi, N.; Kusano, T. NtbZIP60, an endoplasmic reticulum-localized transcription factor, plays a role in the defense response against bacterial pathogens in Nicotiana tabacum. J. Plant Res. 2008, 121, 603-611. [CrossRef]

35. Thurow, C.; Schiermeyer, A.; Krawczyk, S.; Butterbrodt, T.; Nickolov, K.; Gatz, C. Tobacco bZIP transcription factor TGA2.2 and related factor TGA2.1 have distinct roles in plant defense responses and plant development. Plant J. 2005, 44, 100-113. [CrossRef]

36. Tak, H.; Mhatre, M. Cloning and molecular characterization of a putative bZIP transcription factor VvbZIP23 from Vitis vinifera. Protoplasma 2013, 250, 333-345. [CrossRef]

37. Zhang, Y.; Zhang, G.; Xia, N.; Wang, X.J.; Huang, L.L.; Kang, Z.S. Cloning and characterization of a bzip transcription factor gene in wheat and its expression in response to stripe rust pathogen infection and abiotic stresses. Physiol. Mol. Plant Pathol. 2008, 73, 88-94. [CrossRef]

38. Orellana, S.; Yañez, M.; Espinoza, A.; Verdugo, I.; González, E.; Ruiz-Lara, S.; Casaretto, J.A. The transcription factor SIAREB1 confers drought, salt stress tolerance and regulates biotic and abiotic stress-related genes in tomato. Plant Cell Environ. 2010, 33, 2191-2208. [CrossRef]

39. Higuera, J.J.; Garrido, J.; Lekhbou, A.; Arjona, I.; Amil, F.; Mercado, J.A.; Pliego, F.; Muñoz, J.; López, C.J.; Caballero, J.L. The Strawberry FaWRKY1 Transcription Factor Negatively Regulates Resistance to Colletotrichum acutatum in Fruit Upon Infection. Front Plant Sci. 2019, 10, 480. [CrossRef]

40. Zheng, Z.; Qamar, S.A.; Chen, Z.; Mengiste, T. Arabidopsis WRKY33 transcription factor is required for resistance to necrotrophic fungal pathogens. Plant J. 2006, 48, 592-605. [CrossRef]

41. Hu, Y.; Dong, Q.; Yu, D. Arabidopsis WRKY46 coordinates with WRKY70 and WRKY53 in basal resistance against pathogen Pseudomonas syringae. Plant Sci. 2012, 185, 288-297. [CrossRef] [PubMed] 
42. Mehli, L.; Schaart, J.G.; Kjellsen, T.D.; Tran, D.H.; Salentijn, E.M.J.; Iversen, S.T.H. A gene encoding a polygalacturonase-inhibiting protein (pgip) shows developmental regulation and pathogen-induced expression in strawberry. New Phytol. 2004, 163, 99-110. [CrossRef]

43. Khan, A.A.; Shih, D.S. Molecular cloning, characterization and expression analysis of two class II chitinase genes from the strawberry plant. Plant Sci. 2004, 166, 753-762. [CrossRef]

44. Wang, K.; Liao, Y.; Xiong, Q.; Kan, J.; Cao, S.; Zheng, Y. Induction of Direct or Priming Resistance against Botrytis cinerea in Strawberries by $\beta$-Aminobutyric Acid and Their Effects on Sucrose Metabolism. J. Agric. Food Chem. 2016, 64, 5855-5865. [CrossRef]

45. Sornaraj, P.; Luang, S.; Lopato, S.; Hrmova, M. Basic leucine zipper (bZIP) transcription factors involved in abiotic stresses: A molecular model of a wheat bZIP factor and implications of its structure in function. Biochim. Biophys. Acta 2016, 1860, 46-56. [CrossRef]

46. Yin, W.; Cui, P.; Wei, W.; Lin, Y.; Luo, C. Genome-wide identification and analysis of the basic leucine zipper (bZIP) transcription factor gene family in Ustilaginoidea virens. Genome 2017, 60, 1051-1059. [CrossRef]

47. Yang, S.; Xu, K.; Chen, S.; Li, T.; Xia, H.; Chen, L.; Liu, H.; Luo, L. A stress-responsive bZIP transcription factor OsbZIP62 improves drought and oxidative tolerance in rice. BMC Plant Biol. 2019, 19, 260. [CrossRef]

48. Uno, Y.; Furihata, T.; Abe, H.; Yoshida, R.; Shinozaki, K.; Yamaguchi-Shinozaki, K. Arabidopsis basic leucine zipper transcription factors involved in an abscisic acid-dependent signal transduction pathway under drought and high-salinity conditions. Proc. Natl. Acad. Sci. USA 2000, 97, 11632-11637. [CrossRef]

49. Kesarwani, M.; Yoo, J.; Dong, X. Genetic interactions of TGA transcription factors in the regulation of pathogenesis-related genes and disease resistance in Arabidopsis. Plant Physiol. 2007, 144, 336-346. [CrossRef]

50. Liao, Y.; Zou, H.F.; Wei, W.; Hao, Y.J.; Tian, A.G.; Huang, J.; Liu, Y.F.; Zhang, J.S.; Chen, S.Y. Soybean GmbZIP44, GmbZIP62 and GmbZIP78 genes function as negative regulator of ABA signaling and confer salt and freezing tolerance in transgenic Arabidopsis. Planta 2008, 228, 225-240. [CrossRef]

51. Rügner, A.; Frohnmeyer, H.; Näke, C.; Wellmer, F.; Kircher, S.; Schäfer, E.; Harter, K. Isolation and characterization of four novel parsley proteins that interact with the transcriptional regulators CPRF1 and CPRF2. Mol. Genet. Genom. 2001, 265, 964-976. [CrossRef] [PubMed]

52. Chuang, C.F.; Running, M.P.; Williams, R.W.; Meyerowitz, E.M. The PERIANTHIA gene encodes a bZIP protein involved in the determination of floral organ number in Arabidopsis thaliana. Genes Dev. 1999, 13, 334-344. [CrossRef] [PubMed]

53. Wellmer, F.; Schäfer, E.; Harter, K. The DNA binding properties of the parsley bZIP transcription factor CPRF4a are regulated by light. J. Biol. Chem. 2001, 276, 6274-6279. [CrossRef] [PubMed]

54. Chern, M.S.; Bobb, A.J.; Bustos, M.M. The regulator of MAT2 (ROM2) protein binds to early maturation promoters and represses PvALF-activated transcription. Plant Cell 1996, 8, 305-321.

55. Hardtke, C.S.; Gohda, K.; Osterlund, M.T.; Oyama, T.; Okada, K.; Deng, X.W. HY5 stability and activity in arabidopsis is regulated by phosphorylation in its COP1 binding domain. EMBO J. 2000, 19, 4997-5006. [CrossRef]

56. Yin, Y.; Zhu, Q.; Dai, S.; Lamb, C.; Beachy, R.N. RF2a, a bZIP transcriptional activator of the phloem-specific rice tungro bacilliform virus promoter, functions in vascular development. EMBO J. 1997, 16, 5247-5259. [CrossRef]

57. Weltmeier, F.; Rahmani, F.; Ehlert, A.; Dietrich, K.; Schütze, K.; Wang, X.; Chaban, C.; Hanson, J.; Teige, M.; Harter, K.; et al. Expression patterns within the Arabidopsis C/S1 bZIP transcription factor network: Availability of heterodimerization partners controls gene expression during stress response and development. Plant Mol. Biol. 2009, 69, 107-119. [CrossRef]

58. Wang, X.L.; Zhong, Y.; Cheng, Z.M.; Xiong, J.S. Divergence of the bZIP Gene Family in Strawberry, Peach, and Apple Suggests Multiple Modes of Gene Evolution after Duplication. Int. J. Genom. 2015, 2015, 536943. [CrossRef] 
59. Van Verk, M.C.; Neeleman, L.; Bol, J.F.; Linthorst, H.J. Tobacco Transcription Factor NtWRKY12 Interacts with TGA2.2 in vitro and in vivo. Front Plant Sci. 2011, 2, 32. [CrossRef]

60. Jia, H.; Wang, Y.; Sun, M.; Li, B.; Han, Y.; Zhao, Y.; Li, X.; Ding, N.; Li, C.; Ji, W.; et al. Sucrose functions as a signal involved in the regulation of strawberry fruit development and ripening. New Phytol. 2013, 198, 453-465. [CrossRef] article distributed under the terms and conditions of the Creative Commons Attribution (CC BY) license (http://creativecommons.org/licenses/by/4.0/). 